\title{
Place branding y capital cultural: el caso del Barrio Chino de Buenos Aires
}

\author{
Place branding e capital cultural: o caso da Chinatown de \\ Buenos Aires
}

Place branding and cultural capital: the case of Buenos

Aires' Chinatown

Guadalupe Ciocoletto [a] (iD)

[a] Universidad de Buenos Aires, Facultad de Arquitectura, Diseño y Urbanismo, Buenos Aires, Argentina

Cómo citar: Ciocoletto, G. (2021). Place branding y capital cultural: el caso del Barrio Chino de Buenos Aires. urbe. Revista Brasileira de Gestão Urbana, v.13, e20200304. https://doi.org/10.1590/2175-3369.013.e20200304

\section{Resumen}

El artículo que se presenta a continuación aspira a proponer una reflexión sobre la valoración de algunos espacios de la ciudad que poseen una alta carga intercultural. Trabajando sobre las definiciones de algunos conceptos de distintas disciplinas y relacionándolos directamente con un ejemplo de la Ciudad de Buenos Aires se sugiere revisar la lectura de la producción del paisaje urbano en espacios de intercambio cultural, comprendiendo que tanto los elementos como los espacios producidos y recreados desde las distintas culturas son expresiones visibles del patrimonio intangible urbano. Se plantea, desde el ejemplo del Barrio Chino de Buenos Aires, una reflexión sobre la objetivación de algunos bienes culturales en el contexto de la globalización, el uso de lo identitario en función del place branding de la ciudad y sus repercusiones en el imaginario urbano.

Palabras clave: Place branding. Paisaje urbano. Barrio Chino. Buenos Aires.

\section{Resumo}

O artigo a seguir apresentado pretende propor uma reflexão sobre a valorização de alguns espaços da cidade que apresentam uma elevada carga intercultural. Trabalhando nas definições de alguns conceitos de diferentes disciplinas e relacionando-os diretamente a um exemplo da Cidade de Buenos Aires, sugere-se revisar a leitura da produção da paisagem urbana em espaços de intercâmbio cultural, entendendo que tanto os elementos como os espaços produzidos e recriados de diferentes culturas, são expressões visíveis do patrimônio imaterial urbano. A partir do exemplo da Chinatown de Buenos Aires, propõe-se uma reflexão sobre a objetivação de alguns bens culturais no contexto da globalização, o uso da identidade a partir do place branding da cidade e suas repercussões no imaginário urbano.

Palavras-chave: Place branding. Paisagem urbano. Chinatown. Buenos Aires. 


\section{Abstract}

The article presented below aims to propose a reflection on the valuation of some spaces in the city that have a high intercultural load. Working on the definitions of some concepts from different disciplines and relating them directly to an example from the City of Buenos Aires, it is suggested to review the reading of the urban landscape production in spaces of cultural exchange, understanding that both the elements and the spaces produced and recreated from different cultures are visible expressions of the urban intangible heritage. From the example of the Chinatown of Buenos Aires, it is brought forward a reflection on the objectification of some cultural assets in the context of globalization, the use of identity based on the place branding of the city and its repercussions on the urban.

Keywords: Place branding. Urban landscape. Chinatown. Buenos Aires.

\section{Introducción: el paisaje urbano como producción social}

Originado en la necesidad de una relectura de la producción social en el espacio urbano local, el presente estudio tuvo como principales estrategias metodológicas empíricas la revisión de literatura existente sobre el caso de estudio por parte de expertos en el tema desde distintas disciplinas -citados a lo largo del artículo-; la observación y relevamiento de los fenómenos de comunicación intercultural presentes -desarrollado entre 2018-2020- y el análisis de sus usos, variaciones, modificaciones, estado y orígenes, la consecuente elaboración de mapas y gráficos acordes y la comparación de todos estos elementos para la elaboración de conclusiones.

Entendemos al paisaje como una realidad física expresada en una porción de territorio y aprehendida a través de la percepción, tomando a su vez a la subjetividad como elemento primordial de este proceso (Zubelzu Mínguez \& Allende Álvarez, 2015) dado que la percepción se encuentra sujeta a las condiciones -culturales, etarias, de género- de quien la ejerce. La experiencia -en el sentido de experimentación, de exploración, de conocimiento- de los componentes de esa realidad física cobra entonces gran significancia, más aún cuando los entendemos como emergentes de la sociedad que los habita. La Carta del Paisaje de las Américas (Peñalosa et al., 2018) resalta la composición del paisaje como la asociación de sistemas naturales y culturales que funcionan de modo interdependiente apoyando la noción de la importancia de esta interacción.

Por ello, al hablar de paisaje urbano elegimos hacerlo desde la ciudad de todos los días, entendiendo que la idea de que el ambiente construido retrata en su expresión material una determinada interacción entre lo espacial y lo social. Si bien esta no es una apreciación novedosa, lo que se propone en el presente artículo es la articulación de estos conceptos en un ejemplo actual de la Ciudad de Buenos Aires.

La ciudad es una producción física humana que se origina en la realidad social -constituida a su vez por relaciones internas. Estos conceptos debieran ser comprendidos sabiendo que la vida urbana no puede existir sin una base morfológica (Lefebvre, 1974, 1996). Incluso De Certeau (1984) planteaba el reconocimiento a las actividades diarias como elementos de importancia en la construcción de la ciudad y como modo de respuesta contra las formas impuestas, ya sea por parte de los individuos, como también desde los grupos que conforma. Sugerimos, entonces, que existen distintos modos de operación sobre la ciudad, que constituirían innumerables prácticas mediante las cuales se modificará el paisaje urbano en el que se insertan. En el caso de estudio veremos una porción de ciudad cotidianamente habitada y resignificada que carga con modificaciones propuestas desde otros niveles, superponiendo sobre ella otras significaciones. La Figura 1 ilustra algunas escenas de la cotidianeidad del Barrio Chino.

Retomando las definiciones de la Carta del paisaje de las Américas (IFLA AMÉRICAS, 2018) se aprecia la importancia que el paisaje urbano y su protección han tomado en los últimos años. La Carta propone entre sus principios:

Contemplar las singularidades del palimpsesto del territorio en escalas de espacio y de tiempo [...en] el palimpsesto de la contemporaneidad, que se expresa, esencialmente, en las grandes ciudades [...] que vienen exponiendo, en el paisaje, no una relación con los lugares preexistentes, sino en otra escala, con un sistema global (p. 7); 
y entre sus objetivos "Reconocer las ciudades como paisajes urbanos que exigen cuidados y acciones especiales para que puedan cumplir su función social, acogiendo a la población con dignidad, calidad de vida y respetando los límites impuestos por la naturaleza" (Peñalosa et al., 2018, p. 9). La inclusión de las ciudades en relación con el "sistema global" y de su "función social" expone la importancia de una lectura integral de los entornos urbanos, desde su vivencia cotidiana hasta su inserción en el medio globalizado, y propone una visión indivisible de las subjetividades que crean y reforman los entornos urbanos, las subjetividades que lo experimentan y perciben como paisaje y la imagen que ese paisaje proyecta, tanto hacia sus propios habitantes y usuarios como hacia el sistema-mundo donde se inserta.

Hablaremos de espacios de poder, entendiéndolos como aquellos agentes que poseen una posición favorecida en la distribución de capital -sea simbólico, económico, social, cultural o político. Sobre la base de estas diferencias, entendemos, es que se reproducen distancias sociales que afectan el acceso diferencial a ese capital. Esta posición ventajosa, rica en recursos, favorece la influencia sobre otros espacios / agentes, siendo de mayor importancia los modos de relacionarse con los otros actores que el propio capital poseído. En el caso de estudio en cuestión, al mencionar los espacios de poder nos referimos a los gobiernos -chino y local-, corporaciones comerciales, agrupaciones políticas, etc.
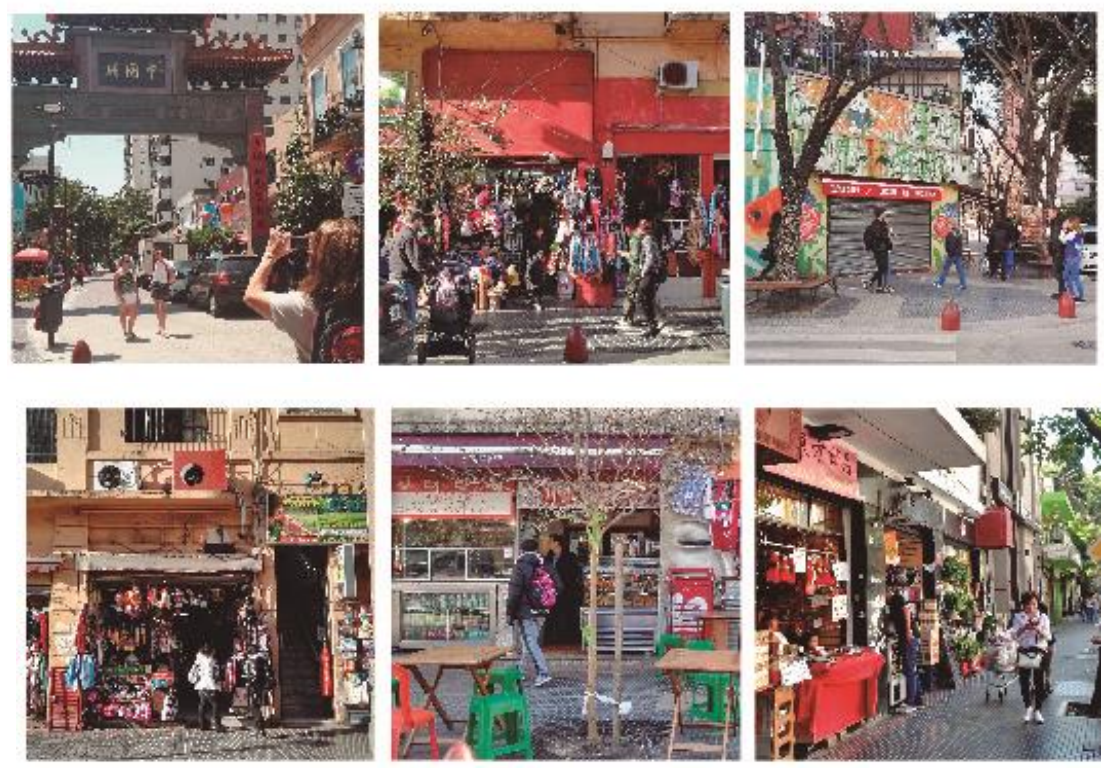

Figura 1 - Imágenes cotidianas del sector estudiado. Fuente: Relevamiento fotográfico del autor (2018-2019).

\section{El Barrio Chino de Buenos Aires}

Escritos de autores especializados en la inmigración china a Buenos Aires (Cechimex, 2018; Brauner \& Torres, 2017b, 2017a; Torres, 2016) la definen como una de las de más reciente llegada, ganando un especial dinamismo en especial desde los años 80 con el arribo de una oleada de inmigrantes taiwaneses -período en el que se origina el Barrio Chino bajo estudio. Posteriormente, en los 90 habría llegado un particular flujo de origen chino-continental. En la actualidad, por su tamaño y siempre según cifras del último censo, es el 12vo. grupo inmigratorio de la Ciudad.

El caso del Barrio Chino se presenta con una característica particular: es el área del territorio con la que se identifica a la comunidad china de la Ciudad, pero, por un lado, no presenta una concentración de personas con ese origen diferente a la que se puede encontrar en otros sectores de la ciudad -las figuras 2 y muestran la concentración de la población china en la ciudad, así como la de las demás principales colectividades de origen extranjero.

En estos mapas, basados en los realizados por Mera y Marcos (2015), se puede observar que la población de origen chino no prevalece ante los otros grupos graficados, que se distribuye homogéneamente dentro de la ciudad, con algunos puntos similares de concentración en el territorio (Figura 2a) y que existen 
en el municipio otros grupos de población extranjera, incluso de mayor proporción numérica, que manifiestan zonas de concentración más concretas y de notable envergadura (Figura 2b). Esto quiere decir que no sería posible designar un Barrio Chino como tal si tomáramos en cuenta solamente los aspectos residenciales de esta comunidad ni tampoco sus dimensiones físicas y que en la zona donde se encuentra el Barrio en cuestión se superponen también otras colectividades. Por el otro lado, tampoco los comercios del Barrio se identifican únicamente con esa colectividad, sino que también reúne negocios de otros orígenes taiwanés, japonés, incluso peruano (Ciocoletto, 2019)-. Y si bien popularmente se reconocen unos pocos sectores de la ciudad como particularmente relacionados con comunidades extranjeras / culturales, desde los espacios oficiales el uso turístico del término Barrio se da sólo en dos casos: el del Chino y el del Judío (Ente de Turismo de la Ciudad de Buenos Aires, 2013a, 2016).

Como afirmaran Nogué et al. (2019, p. 86) "La toponimia y el nombre que la población adjudica a algunos paisajes contiene una elevada carga de valores simbólicos e identitarios" y éste sería un claro ejemplo. La denominación que se le ha dado refiere más a un intento de equipararlo con otros Barrios Chinos / Chinatowns del mundo -que mayormente sí cumplen con ser espacios de residencia de la comunidad-, lo que apoyaría también las ideas expresadas por Anholt (2010a) en cuanto a que algunos lugares son nombrados deliberadamente para venderse de manera más efectiva a un público específico y que muchos nombres de lugares son un tipo de marca: las personas responden a ellos como responden a los nombres comerciales de otros productos.

Si bien el Barrio Chino caería bajo la definición de barrio étnico de acuerdo con Sassone \& Mera (2007, p. 2) dado que se conforma sobre la base de las relaciones personales solidificadas por las redes migratorias, Laborde (2011) propone otro punto de vista: el término barrio étnico referiría a un tipo de aislamiento urbano que no se da en el caso del Barrio Chino donde "el espacio de exclusión estaría dado ya no por una situación de confinamiento espacial de los inmigrantes al estilo gueto o barrio étnico sino por la operación simbólica e ideológica que actúa sobre los sujetos constituyéndolos como inmigrantes" (p. 39). Esa "operación simbólica", en este caso, vendría dada tanto por los propios comerciantes, habitantes y usuarios del Barrio -ver Figura 3como desde los espacios de poder que se detallarán más adelante (Grimson et al., 2016).

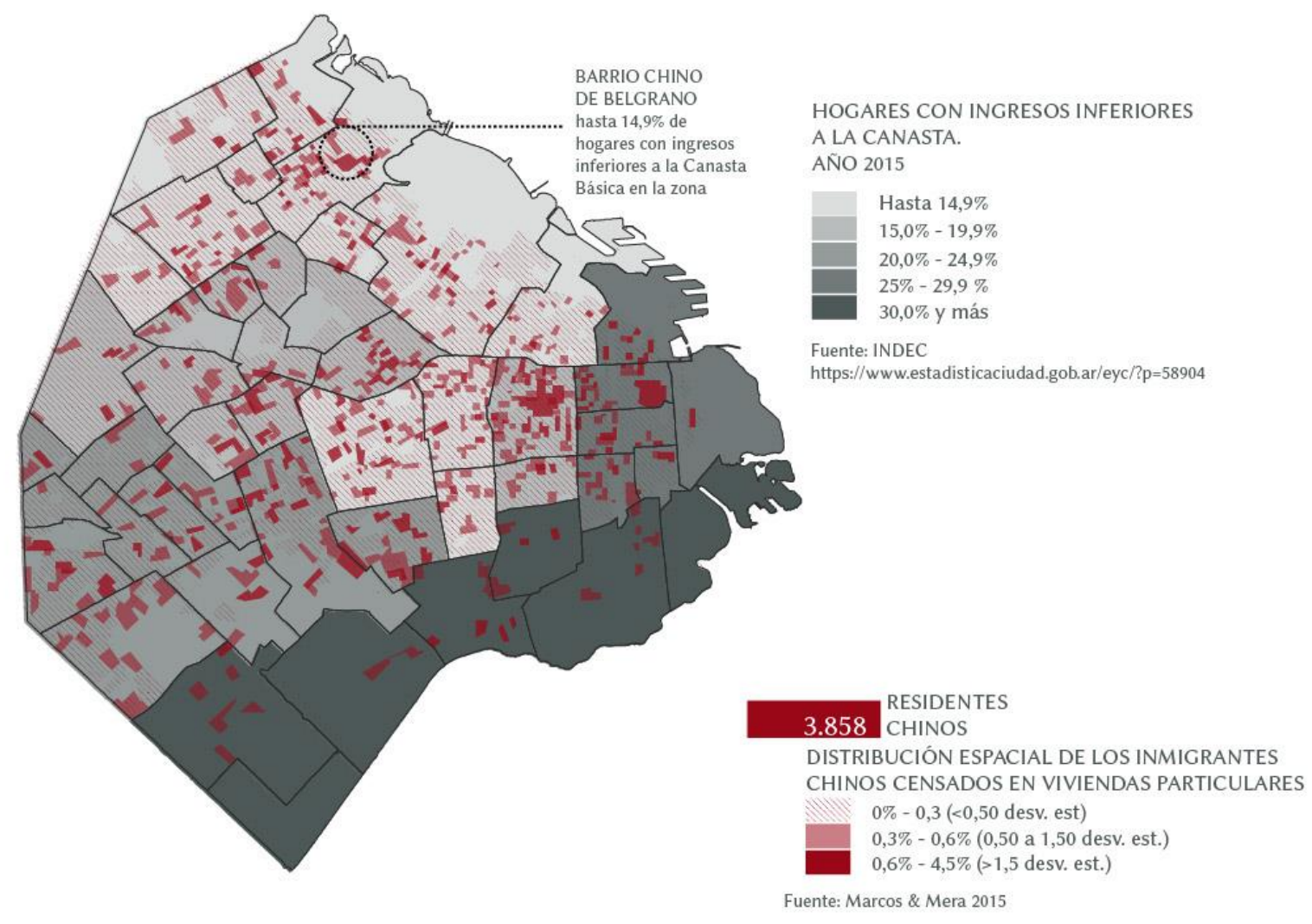

Figura 2a - Concentración de la población china en la Ciudad de Buenos Aires. Fuente: Elaboración propia en base al estudio de Mera y Marcos (2015) e INDEC (2010). 
A pesar de que mayormente contiene comercios y restaurantes -que no exclusivamente se identifican con la colectividad china, sino también con la de otros países asiáticos como se evidencia en la existencia de restoranes de comida Japonesa, Tailandesa y Vietnamita- el Barrio también circunscribe funciones religiosas y culturales en templos, escuelas y galerías -y aquí otro ejemplo de la variedad de naciones representadas es la presencia de la Asociación Civil de los Taiwaneses en Argentina (aunque argentina no reconozca a Taiwán como país independiente)- que con el correr del tiempo han ido abriendo sus puertas e incluyendo a la comunidad local en algunas de sus actividades. Es así que para Brauner \& Torres (2017a, p. 659) "su función es principalmente comercial y cultural, comunitaria en menor medida y extracomunitaria en su estrategia dominante".

Dentro de esta función extracomunitaria, entendemos, se encuentra incluida la turística que ha crecido durante los últimos años y el Barrio se ha transformado, así, en un punto de atracción importante dentro de la ciudad. La visita al Barrio Chino es publicitada desde las páginas oficiales del Gobierno (Ente de Turismo de la Ciudad de Buenos Aires, 2013a, 2013b, 2020). El origen de la función turística, según la tesis de González Viaña (2013), se habría dado gracias a un cambio en la vocación del espacio; mientras por otro lado, para Baisotti \& Yan la creciente convocatoria "se debe, en parte, al trabajo de la segunda generación de inmigrantes chinos que dotó al "Barrio Chino" de un estilo más autóctono y actual" (2017, p. 16). Entendemos que podría ser, en realidad, una síntesis de ambas: el cambio de vocación sería el resultado de una contemporánea tendencia al turismo globalizado, a la vez que tanto las segundas generaciones como los espacios de poder -gobiernos locales y chinos- estarían modificando los sectores urbanos en pos de esta necesidad. Reforzando esta idea, Sassone \& Mera afirman que "el barrio chino utiliza la diferencia cultural como marca de consumo particular dentro de la Ciudad" (2007, p. 10).

El Barrio es, entonces, visitado por una variedad de públicos. En los días festivos como el Año Nuevo Lunar llegan a la zona habitantes de la ciudad y alrededores que desean ser parte de los festejos. Algo similar, pero en cantidad de visitantes mucho menor, sucede los fines de semana cuando asisten también familias y paseantes, que al encontrar la calle principal peatonalizada se topan con un paseo que no obliga a grandes gastos. El resto de los días también concurren al lugar públicos variados: turistas -mayormente población local, pero también internacionales-, oficinistas que consumen en los locales de comidas, personas chinas o identificadas con esa cultura que se acercan para conseguir productos típicos especialmente alimenticios- que en otras partes no se consiguen. También son de especial interés para el consumidor local de clase media los supermercados y pescaderías.

Las distintas formas de expresión cultural transforman a este espacio en un lugar con significado de sinidad. Este sector es reconocido por residentes y turistas como el lugar chino de la ciudad, pero no sería solo eso: también los estudios citados entienden al Barrio Chino como una pieza importante de la representación de la población china local. A pesar de no encarnar hoy en día la localización residencial de la población china, retrata parte de su cultura en sus celebraciones, tradiciones alimentarias y su característica comercial -y no únicamente por la presencia de comercios, sino también por la de organizaciones que los nuclean. En apoyo de las actividades representativas se puede apreciar el carácter altamente comunicativo de las esculturas y el arco de entrada, las fachadas con sus murales y los objetos expuestos en las vidrieras. Los elementos percibidos a través de los canales verbales y no-verbal / visual se repiten en particular sobre la calle principal, aunque también en algunos comercios de las calles aledañas. 


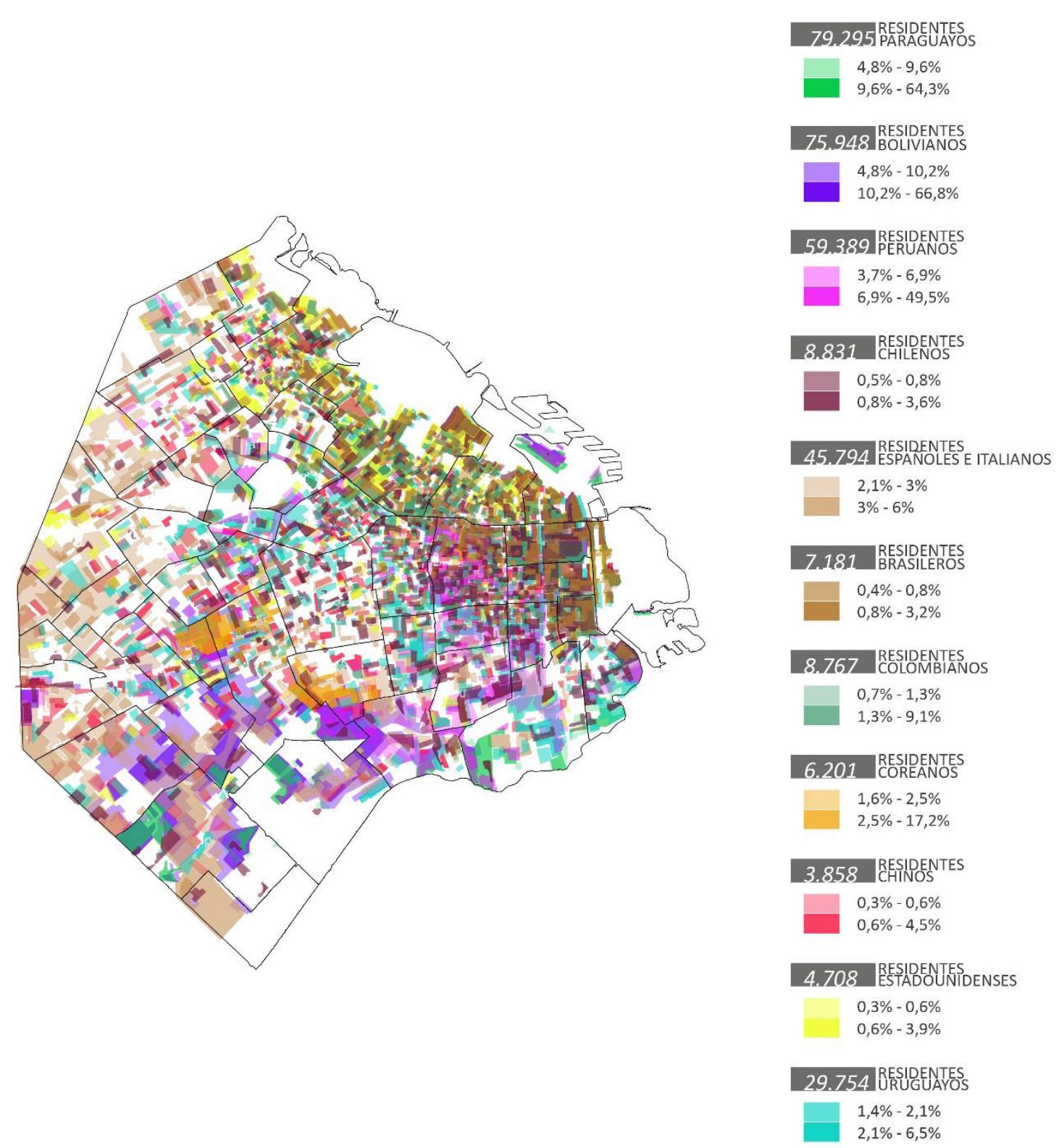

Figura $\mathbf{2 b}$ - Concentración de las distintas colectividades en la ciudad de Buenos Aires. Fuente: Elaboración propia en base al estudio de Marcos \& Mera (2015).

Podemos afirmar que, simultáneamente, los espacios de poder han intervenido en este espacio de distintas maneras: en el Barrio Chino encontramos elementos que han sido brindados por los gobiernos locales y representantes chinos, que no solo hacen al confort -mobiliario, iluminación especial para peatones, señalización de todas las calles, elementos que ordenan la circulación y el estacionamiento vehicular-, sino incluso otros con significado socialmente compartido como representantes de lo "oriental" -el arco de acceso y al menos otras seis esculturas que fueron donados por el Gobierno de China, carteles con dragones de color rojo, señalética con los nombres de las calles traducidos al alfabeto chino, etc. (ver Figura 4)-. De esta forma, y sumando la invitación al turismo que se hace desde sitios web oficiales, el Barrio Chino ha ganado en solidez simbólica ante la toda la comunidad de la Ciudad más allá de su origen o cultura. Algunas modificaciones se ejemplifican en la Figura 5. Preliminarmente, podemos afirmar que tenemos bajo estudio un área de alteridad simultáneamente controlada y fomentada, donde la identidad cultural viene reforzada verticalmente por entidades que están por sobre los usuarios del espacio (Ciocoletto, 2018). 
a)

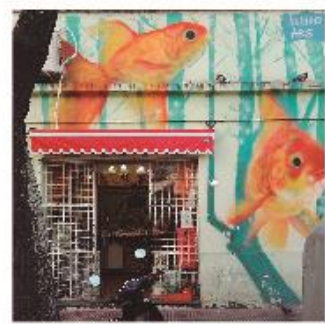

b)

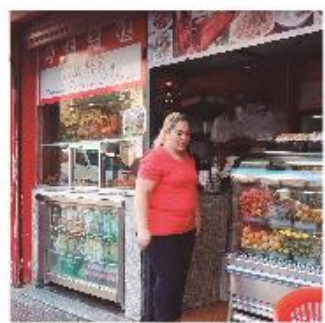

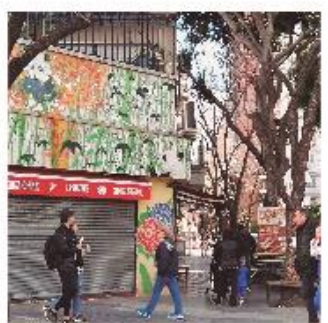

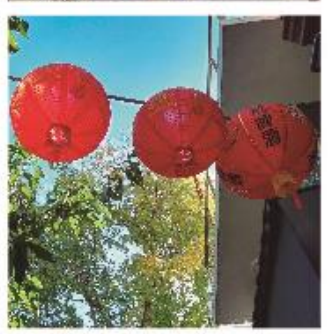

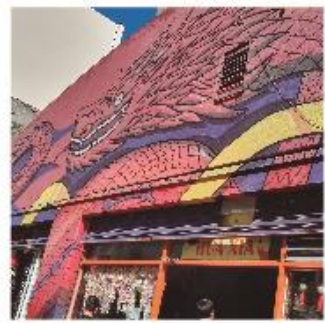

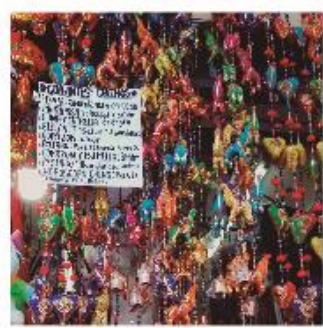

Figura 3 - operaciones simbólicas por parte de comerciantes y usuarios. a) murales alegóricos comisionados a artistas plásticos; b) exhibición de ornamentos, simbologías y colores identificados con la cultura china. Fuente: Relevamiento fotográfico del autor (2018-2019).

\section{La cultura como atractivo: apelar a lo intangible y lo emocional}

Las soluciones urbanas desde la operación sobre proyectos culturales serían ya repetidas en las ciudades modernas. Y en el caso de la Ciudad de Buenos Aires, según afirma en su tesis Dinardi (2012), la Cultura se habría convertido en la panacea contemporánea a través de la cual la ciudad pretendería subsanar sus dificultades, intentando copiar los beneficios estéticos, económicos y de recuperación urbana que este modo de operar habría también traído a otras ciudades -Bilbao, Barcelona y Nueva York entre otras-. Afirma Dinardi que

Esta re-significación de lo moderno es vital para comprender el lugar asignado a las actividades culturales en la retórica política local y para resaltar el significado cambiante de la modernidad en Argentina. La cultura, en la forma del barrio cultural o el museo icónico, está en el corazón de una nueva modernidad de las ciudades y es el mejor producto para alimentar campañas de marketing urbano $^{1}$. (2012, p. 30)

Al reproducir este tipo de estrategias, la Ciudad de Buenos Aires estaría obedeciendo a un modus operandi de place branding globalmente desarrollado.

Mayormente, en los últimos años -caracterizados por el capitalismo postindustrial y la globalización- la cultura y las artes se han transformado en una excusa para el desarrollo urbano, pretexto a través del cual viejas fábricas, áreas degradadas o antiguos asentamientos se han revalorizado otorgándoles una nueva función artística o cultural -museos, centros sociales, polos artísticos o tecnológicos-. De este tipo de iniciativas pueden formar parte tanto gobiernos locales como organizaciones privadas y también grupos comunitarios. Son en muchos casos parte de estrategias urbanas más amplias para revitalizar centros históricos, revalorizar el patrimonio cultural y crear nuevos recursos para el turismo y la inversión empresarial (Dinardi, 2012). Y en relación al aspecto económico, la cultura se transformaría en un medio más que en un fin en la medida en que "desempeña un papel crucial en la venta de lugares, ya que

\footnotetext{
1 Traducción propia del original en inglés "This re-signification of the modern is vital to understanding the place assigned to cultural activities in the local political rhetoric and to highlight the changing meaning of modernity in Argentina. Culture, in the form of the cultural quarter or the iconic museum, is at the heart of a new modernity of cities and the best commodity with which to feed urban marketing campaigns."
} 
proporciona el contenido simbólico para la construcción de la imagen de la ciudad, que es utilizada por funcionarios públicos y consultores con fines de marketing"2 (Dinardi, 2012, p. 48).
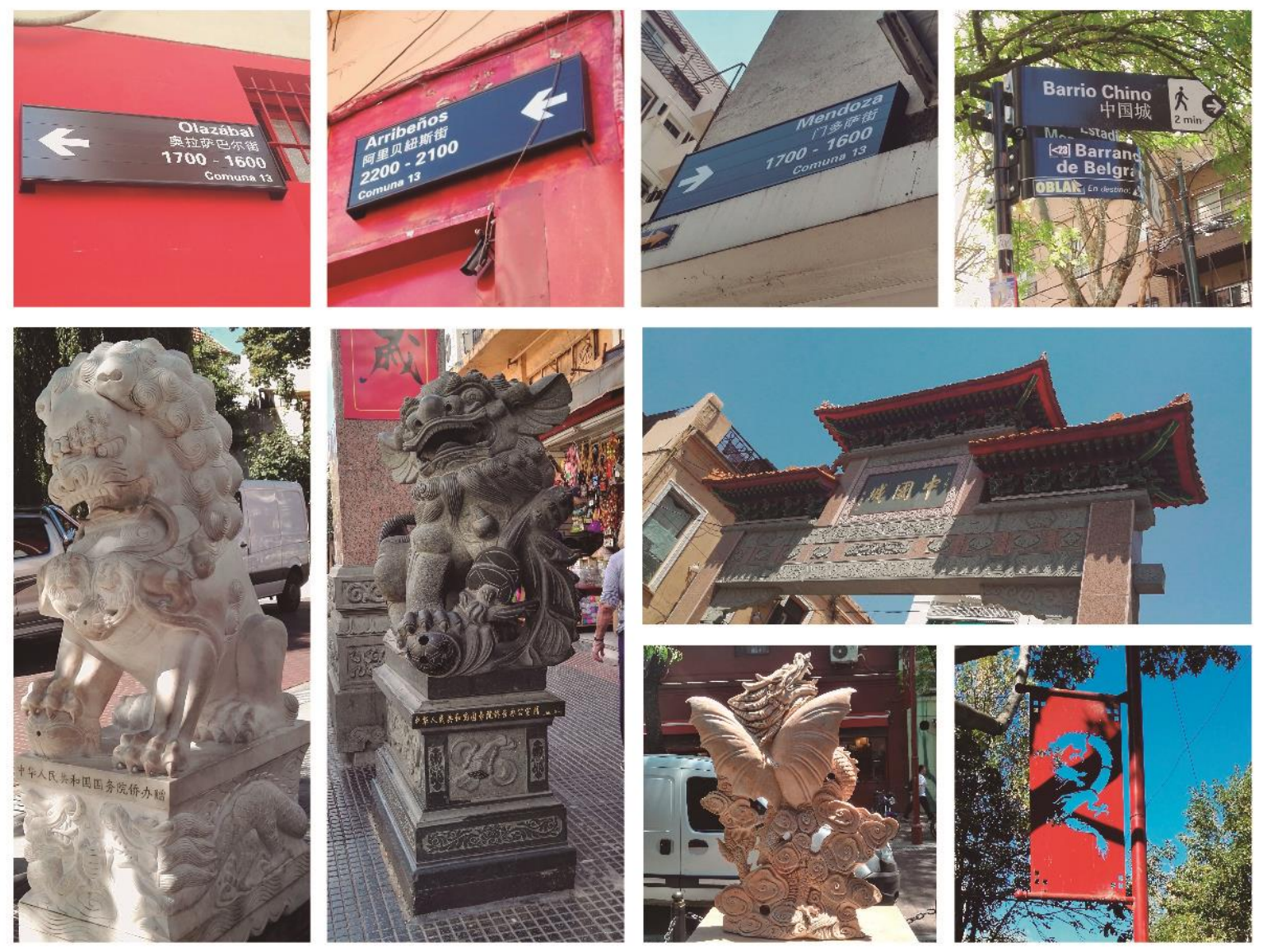

Figura 4 - Elementos del Barrio Chino cedidos por Espacios de Poder. Señalética traducida al alfabeto chino, esculturas, Arco de Ingreso, carteles decorativos. Fuente: Relevamiento fotográfico del autor (2019).

La revitalización habría sido también parte de la justificación para las modificaciones producidas en el caso bajo análisis. Resulta evidente en el ejemplo del Barrio Chino -sobre el cual hemos visto se ha operado largamente y donde el énfasis en lo cultural resulta evidente, a pesar de no haber sido una zona particularmente degradada que necesitara ser reformulada, sino que ha pertenecido históricamente a la zona más pudiente de la ciudad. El beneficio para la Ciudad no habría estado en el hecho particular de la mejora sino en el atractivo turístico que ésta habría proporcionado.

Operar sobre lo cultural en lo urbano -y el turismo cultural también sería un ejemplo de ello-, implicaría igualmente operar sobre la historia, el patrimonio y la memoria de los lugares y las ciudades: lo material y lo intangible. El tratamiento de las características culturales de una ciudad plantea también la cuestión sobre la su verdadera historia, lo patrimoniable, la memoria, la herencia cultural y la representación.

\footnotetext{
${ }^{2}$ Traducción propia del original en inglés "culture plays a crucial role in the selling of places as it provides the symbolic content for the construction of the city's image, which is used by civil servants and consultants for marketing purposes."
} 


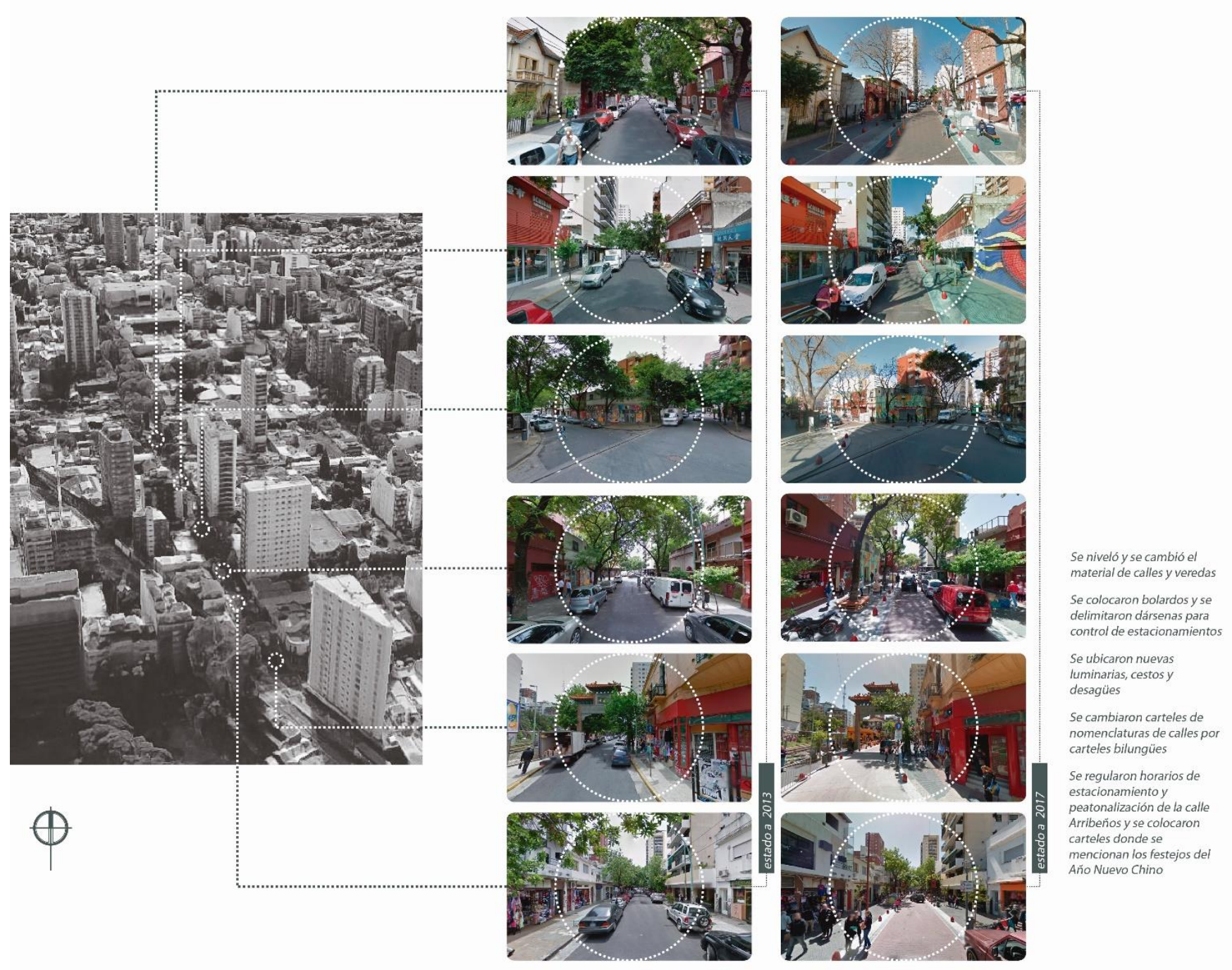

Figura 5 - Modificaciones en el Barrio Chino 2013-2017. Relevamiento de modificaciones en la Calle Arribeños entre 2013 y 2017. Fuente: Relevamiento propio del autor a partir de visitas al lugar e imágenes existentes en Google Street View.

El paisaje, como hemos mencionado, propone una lectura desde lo experiencial, y en ello cobra importancia la interacción entre las personas y el espacio. Además, se concibe como la representación que de él hace la población (Nogué et al., 2019) y en este sentido es necesario destacar la importancia de su capacidad didáctica: el paisaje comunica, la ciudad comparte información, tiene un discurso y un contenido ético que transmitir. Nogué y de San Eugenio Vela (2010, p. 18) proponen que:

(...) en el contexto de determinadas localizaciones, se desarrollan un conjunto de procesos de comunicación (a nivel intra e interpersonal), condicionados por el propio territorio, el cual mediatiza, sin duda, la acción comunicativa. Así pues, la interacción humana con el espacio que le es propio (territorios de la cotidianeidad) y con el espacio que le es ajeno (territorios de lo desconocido) posee, en ambos casos, connotaciones comunicativas que también se deberán tener en cuenta.

En esa comunicación encontramos, en la visión de Folch-Serra (2007, p. 140) que "El paisaje es, así, un palimpsesto cuyas capas culturales, por no mencionar las geológicas, se sobreponen unas a otras" y si bien Folch-Serra habla de la imagen de nación, creemos que lo mismo sucede a nivel ciudad, espacio de disputa de imaginarios urbanos particulares -especialmente en el caso de ciudades como Buenos Aires, la cara más visible y la puerta de entrada del turismo que llega al país-.

Es por esta razón que nos preguntamos en cuanto al caso particular bajo estudio, ¿cómo se ha modificado el espacio de interacción intercultural? Y en términos más generales ¿qué mensaje se busca transmitir en la operación sobre el paisaje urbano de la ciudad? 
El espacio en cuestión posee una carga simbólica profusa, nacida tanto desde la comunidad de comerciantes como desde los espacios de poder, en ambos casos con la intención de atracción. La apelación a la carga cultural del Barrio Chino por parte de las autoridades locales buscando promocionar una imagen de ciudad global, con diversidad cultural, moderna; y también del del Gobierno Chino, como muestra de su presencia, como señal de apoyo a la población de ese origen que reside en la ciudad, buscarían influir en las subjetividades de quienes lo conocen -ya sea desde la experiencia presencial, como a través de las imágenes publicitadas-. "Carga que se manifiesta tanto en la materialidad de cada fisionomía modelada por la acción humana, como en sus imágenes y representaciones sociales, modelos paisajísticos y de preferencias" (Zubelzu Mínguez \& Allende Álvarez, 2015, p. 3)

Estos elementos participan de la comunicación intra e intercultural, condicionando la imagen del Barrio y se convierten en mediadores de un mensaje. Dada la naturaleza comercial y turística del área, este mensaje posee particularmente un tinte promocional. En este sentido, Nogué y de San Eugenio Vela (2010) vinculan al concepto de paisaje con el de identidad territorial: "El paisaje, por tanto, se está convirtiendo, cada vez más, en un producto de consumo per se, exaltando la experiencia con el territorio, así como la búsqueda de nuevas sensaciones" (p. 27).

\section{Objetivación del capital cultural urbano y consumo}

Luego de haber mencionado el rol de los espacios de poder en la toma de decisiones y de relacionarlas con cierto control ejercido sobre este espacio público en particular, estamos en condiciones de introducir el concepto de la objetivación de algunas de las expresiones culturales encontradas.

Para comprender las relaciones de dominación, Bourdieu (2018) estudia las estrategias -conscientes e inconscientes- en que las clases procuran conservar o mejorar sus condiciones. Distingue en su obra entre cuatro formas de capital: el capital económico -donde encontramos los factores de producción y bienes económicos-, el capital social -que incluye el conjunto de relaciones sociales-, el capital simbólico -los rituales de honor y reconocimiento- y el capital cultural -en donde están las calificaciones intelectuales-. Cuando refiere a este último en su estado objetivado, representa al capital cultural convertido en soportes materiales -libros, diccionarios y otros instrumentos de conocimiento-. Entendemos entonces, en este trabajo, a los espacios públicos como parte del capital cultural ya que los estudiamos como espacios didácticos comunicativos y de conocimiento. Su objetivación la encontramos en la transformación de sus elementos comunicativos convertidos a soportes materiales, transformados en instrumentos físicos portadores de un mensaje. Se daría también, en algunos casos, lo que Bourdieu llama alquimia social: esto es, la transformación de relaciones arbitrarias en legítimas y de diferencias de hecho en oficialmente reconocidas. Por otro lado, para perpetuar cierto orden de poder se impondrían, además, reglas desde la relación de dominación. Según esta teoría, agentes diferentes en contextos diferentes pondrían en práctica diversas estrategias de reproducción social como un modo de reproducir sus capitales. Dentro de estas estrategias -que se encuentran en todas las sociedades y que varían según la índole del capital a transmitirencontramos las de inversión simbólica que "apuntan a conservar y aumentar el capital de reconocimiento" (Bourdieu, 2018, p. 37) favoreciendo esquemas de percepción favorables y positivos.

Volviendo a nuestro caso de estudio y tomando como base los conceptos de capital cultural y en especial el objetivado, podemos encontrar una evidente relación entre el capital cultural y el simbólico, en tanto la proliferación de elementos de capital cultural objetivado dispensados por los espacios de poder refieren a y fomentan el capital simbólico y el ritual de reconocimiento hacia la población china dentro del espacio urbano. La posesión del capital simbólico asegura la posesión de una riqueza duradera y con ella una forma de lograr ejercer un cierto tipo de poder -el atractivo turístico, por ejemplo-. A su vez, esto repercutiría en el capital económico en tanto aumenta -o posibilita el incremento de- los factores de producción desde la promoción del consumo en dichos espacios. Por su parte, el capital social -entendido como conjunto de relaciones socialesse ve también afectado por el reconocimiento del capital simbólico: en el caso del Barrio Chino, de gran promoción, este capital social se demuestra en la relación entre la comunidad China y los espacios de poder 
locales y extranjeros, y en la relación de conocimiento de las personas que no habitan el lugar pero que aun así reconocen el valor dado a este rincón de la ciudad. Si nos basamos en lo planteado por Bourdieu podemos reforzar la idea de que quien articula los bienes culturales, sobre todo objetivados, posee junto con ellos un poder que se demuestra en la dominación de otros agentes y en la regeneración de la propia riqueza. Ésta, entendemos, puede ser cultural, económica o de relaciones con otros espacios de poder.

El caso del Barrio Chino sería también un ejemplo de la alquimia social, dadas las intervenciones que ha experimentado. Podríamos afirmar, luego de las reflexiones propuestas, que allí primeramente se habrían delimitado y resaltado las diferencias culturales entre locales y orientales ${ }^{3}$ en función de atraer al turismo y al consumo -capital simbólico. Si bien la propuesta de ley para delimitar con exactitud al barrio no ha prosperado, la existencia del Arco de ingreso, las demarcaciones de las intervenciones de decoración y peatonalización -capital cultural objetivado-, así como las descripciones que se hacen sobre el barrio en los portales de turismo -capital simbólico- con características específicas, hablan, a la vez, de un lugar bien determinado dentro del territorio de la Ciudad, lo que acentuaría su objetivación, en correspondencia con las características de marcas ya mencionadas de Anholt (2006). En cuanto a la autenticidad de esa demarcación, podemos aportar un pensamiento de Delgado Ruiz: "Esa presunción de la ciudad como zonificada en áreas en las que vivirían acuarteladas comunidades con una identidad étnica o religiosa compartida, ha ocultado una realidad mucho más dinámica e inestable" (1999, p. 43). Podríamos ampliar: la idea de identificar a una comunidad como confinada a un espacio urbano determinado, como lo hemos ya mencionado, ocultaría las relaciones interculturales e hibrideces que demuestran que lo chino excede estos pretendidos límites -como se ha comentado, los focos de concentración de población china se distribuyen homogéneamente en el territorio de la Ciudad- y que tampoco es exclusivamente expresión de sinidad dentro de ellos -las celebraciones de Año Nuevo son parte ya de las festividades convocadas por el gobierno local, diversas mercancías y locales comerciales se identifican con otros orígenes o proponen productos fusionados. Al mismo tiempo, encubriría las problemáticas de la propia colectividad en relación a otros grupos que suceden dentro del barrio - como por ejemplo la aprobación de la ubicación del Arco de ingreso fue tomado como una invasión no sólo por los vecinos de Belgrano que denunciaron ante la Procuración General de la Ciudad que el arco habría sido instalado de forma ilegal (Asociación Civil Vecinos de Belgrano, s. f.); sino también por los taiwaneses que habrían visto en este arco y la oficialización del sector como Barrio Chino una toma de posición de la población china ocupando espacios que históricamente habrían sido identificados con la taiwanesa (Grimson et al., 2016), y la celebración del Año Nuevo desdoblada en dos festejos separados: uno para la colectividad china, otro para la taiwanesa.

\section{Entre las lógicas del branding y el embodiment}

Si bien de acuerdo con Anholt (2010a), todavía no se ha llegado a un consenso sobre la definición exacta de place branding, nos manejaremos aquí con aproximaciones que el autor propone y que seguramente sean trabajadas en mayor profundidad a futuro. Una de ellas es que históricamente los lugares -ciudades, paísesse han abocado competir por los consumidores externos, buscando no solamente influenciar opiniones positivas sino también el respeto y la atención de los medios. Así hasta la actualidad, los lugares han tenido la necesidad de promoverse como atractivos, funcionando y promocionándose como empresas para responder adecuadamente a las amenazas de la competencia y a los cambios globales de manera efectiva. El tratamiento de los lugares ya no se daría como simplemente promocionados, sino como productosmarcas (branding). El branding de un lugar incluiría una denominación-marca, una identidad visual y además acciones para mejorar la imagen de marca del lugar haciendo de ellos lugares memorables.

Para Nogué \& de San Eugenio Vela "place branding se entiende como una posible respuesta a la necesidad de impregnar a los espacios de la posmodernidad de 'simbologías consumibles'” (2017, p. 145) o

\footnotetext{
${ }^{3}$ En el sentido de orientalismo de Edward Said (2002), quien lo define como una mirada desde occidente según la cual, entre otras cosas, se le ha dado a oriente una identidad construida desde estereotipos que se suponen estables y continuos.
} 
bien "geografías consumibles" refiriendo a ciertos procesos "de consumo directo y/o mediado de espacios geográficos, íntimamente vinculados a renovadas estrategias de promoción y/o comercialización del paisaje y a su capacidad para generar proyecciones e imaginarios territoriales" (2017, p. 148). Esta visión agrega a las anteriores la carga consumista posmoderna, ya no de productos y lugares sino también de imaginarios.

En cuanto al rol de los espacios de poder en el branding de los lugares, según observa Anholt en la mayoría de las economías de mercado el gobierno simplemente proporciona una "marca" (brand) general sobre los proveedores privados de servicios, destinos y atracciones comercializados (marketed) en el campo de lo privado. Lo que realmente cuenta, en definitiva, es controlar la imaginación del cliente con una propuesta única y atractiva que represente una licencia para hacer negocios con él (Anholt, 2006).

En definitiva, la conversión de los lugares de la ciudad en espacios consumibles con la idea de transformarlos en productos competitivos en el mercado -turístico, cultural y económico- global. Es interesante retomar aquí a los principios de la Carta del Paisaje buscando entender a las ciudades en su inserción al sistema global, y reflexionar sobre los paisajes generados como productos para esa inserción. Nos encontramos así frente a la dualidad de lugares/productos con características de marcas (brands) comerciales -claridad, simplicidad, memorabilidad, peculiaridad (Anholt, 2010b, p. 178)- y la de su percepción que ha sido direccionada por los espacios de poder.

Desde el punto de vista de las experiencias y las percepciones, podemos acercar el concepto de place embodiment -como encarnación, incorporación- de lo comunicado por ese paisaje que de acuerdo con Nogué y de San Eugenio Vela (2017) además implica aspectos sensoriales, emocionales y cognitivos, colocando una pronunciada importancia en el proceso de construcción social de los lugares. Y si bien los estudios sobre las ciudades han mayormente dejado de la lado el aspecto de lo sensorial y de lo afectivo, el reciente interés en revisar los espacios urbanos desde estos atributos permite comprender las intervenciones cada vez más sofisticadas que suceden en varios registros de la vida urbana (Thrift, 2004). El concepto de place embodiment aborda no sólo lo cognitivo sino que "implica el replanteamiento de la forma mediante la cual los ciudadanos viven, consumen y, en definitiva, se imbuyen de sus espacios geográficos" (Nogué \& de San Eugenio Vela, 2017, p. 149) y permite reconocer que los espacios son incorporados al imaginario y a la esfera de lo emotivo a través las posibilidades experimentales que brindan.

Entendemos que la revisión del presente caso de estudio se ajusta a las expresiones propuestas desde el branding en tanto contiene un nombre aceptado y promocionado -inclusive en 2005 se presentó el Proyecto de Ley 402-D-2005 (2005) ante la legislatura porteña, que solicitaba se denominase oficialmente a los fines turísticos y promocionales a este sector de la ciudad como "Barrio Chino"-, una identidad visualsimbólica reconocible y reproducida desde los espacios de poder, y además acciones desde los mismos espacios que invitan a experimentarlo -invitaciones y presencias oficiales en las celebraciones del Año Nuevo Lunar, por ejemplo-; Y desde el embodiment, en cuanto que los símbolos culturales dispuestos, aromas, colores, invitaciones a celebraciones, intervienen la experiencia sensorial y refuerzan la incorporación de este espacio en la memoria sensible.

Estas maniobras apartan de la imagen comerciada del Barrio Chino las discrepancias que existen con los vecinos de los alrededores; o incluso la discriminación que ha sufrido la población china en la ciudad que ha sido relacionada con la existencia de mafias, sumada a la reputación de ilegalidad de algunos de sus productos. La imagen del lugar/producto comerciado permanece así distintiva, memorable e impoluta. Lo comerciado, además, tiene que ver solamente con lo chino y no ya con sus hibrideces, con sus relaciones con lo local, sus espacios intermedios.

\section{Conclusiones: imaginario cultural y patrimonio}

El capital urbano condensa el pasado heredado, el presente en vivencia y el futuro como legado. Entendemos en este trabajo a la expresión urbana de los aspectos culturales en cuanto a memoria valorada, memoria creada, y de esta forma relacionada con lo patrimonial y lo patrimoniable. Cada comunidad 
interpreta ese pasado cultural y comunica ese testimonio de una manera particular y lo mismo sucede desde los espacios de poder, que deciden sobre lo valorable -y por tanto, patrimoniable- de cada ciudad.

La operación desde los espacios de poder sobre los elementos culturales -y de la comunicación intercultural- en función del place branding/embodiment podría modificar la percepción sobre los lugares y las colectividades que los ocupan. En un marco como el de la Ciudad de Buenos Aires, con presencia de múltiples identidades culturales -que tienen, además, situaciones espacial y económicamente diferentessería posible afirmar que la facilitación de elementos simbólicos culturales representativos junto a la promoción de una imagen urbana positiva que busca, además, invocar aspectos emotivos, podría actuar en favor de algunos espacios urbanos y en detrimento de otros que no han recibido el mismo tratamiento, fomentando un reconocimiento desigual por parte de terceros de cada colectividad y su espacio según intereses particulares.

En el caso específico del Barrio Chino de Buenos Aires, el estado objetivado de algunos de sus elementos culturales desde los espacios de poder en favor del ya discutido branding asigna una carga característica a la percepción -embodiment- del paisaje. A veces, podríamos decir, incluso de forma engañosa: es conocido como barrio mientras es un espacio particularmente comercial, y reconocido como espacio de lo chino dejando en segundo plano otras culturas participantes y matices, por ejemplo.

Creemos que sea pertinente reflexionar sobre los modos de operar en los paisajes culturales de la ciudad, evaluando en qué manera éstos influyen sobre el patrimonio intercultural históricamente intrínseco a Buenos Aires, de modo de potenciar sus características sin crear paisajes artificiales o imaginarios simulados. Para ello sería necesario un más profundo entendimiento de sus reales características y necesidades, cuidando su capacidad didáctica comunicativa, allende los objetivos comerciales o promocionales.

Como afirmara Nogué (2007, p. 136) "el hecho es que las interconexiones entre las fuerzas globales y las particularidades locales alteran las relaciones entre identidad, significado y lugar" y posteriormente Nogué y de San Eugenio Vela "Lo realmente novedoso es el establecimiento de mecanismos de control y/o apropiación de la mirada hacia un paisaje, la inducción de imaginarios de paisaje” (2017, p. 147). En definitiva, la decisión sobre los significados y mensajes transmitidos, sobre lo memorable -y en consecuencia, sobre lo patrimoniable- es una decisión política cuyas implicancias merecen especial atención de todos los sectores.

\section{Referencias}

Anholt, S. (2006). Is place branding a capitalist tool? Place Branding and Public Diplomacy, 2(1), 1-4. https://doi.org/10.1057/palgrave.pb.5990039

Anholt, S. (2010a). Definitions of place branding - Working towards a resolution. Place Branding and Public Diplomacy, 6(1), 1-10. https://doi.org/10.1057/pb.2010.3

Anholt, S. (2010b). Place image as a normative construct; and some new ethical considerations for the field. Place Branding and Public Diplomacy, 6(3), 177-181. https://doi.org/10.1057/pb.2010.26

Asociación Civil Vecinos de Belgrano. (n.d.). Un antro de corrupción, habilitaciones fraguadas, procedimientos mafiosos. Recuperado el 17 de octubre de 2018 de http://belgranodenuncia.blogspot.com/

Baisotti, P., \& Yan, E. (2017). La inmigración china en la Argentina. "Puentes" y sincretismo cultural. Recuperado el 30 de noviembre de 2018 de https://www.researchgate.net/publication/320008980\%0ALa

Bourdieu, P. (2018). Las estrategias de la reproducción social. (Alicia B. Gutiérrez trad., Ed.) (1a. ed. 2a). Buenos Aires: Siglo XXI Editores.

Brauner, S., \& Torres, R. A. (2017a). Identidades chinas en Buenos Aires: taiwaneses, chinos continentales y "argenchinos". Santiago, Septiembre (144), 652-665. Recuperado el 30 de noviembre de 2018 de https://santiago.uo.edu.cu/index.php/stgo/article/view/2910/2606

Brauner, S., \& Torres, R. A. (2017b). Los chinos y sus descendientes en Buenos Aires. Diversidades identitarias en una de las 
comunidades chinas de ultramar (entre fines de los años setenta del siglo XX e inicios del XXI). Diversidad, 13(JunioDiciembre), 70-87. Recuperado el 20 de Abril de 2019 de http://www.diversidadcultural.net/articulos/nro013/13-05Dra-Susana-Brauner.pdf

Centro de Estudios China-México de UNAM (Cechimex) (2018, 31 ene.). Identidades chinas en Buenos Aires: Susana Brauner [Video]. Youtube. https://www.youtube.com/watch?v=s8EehtYOh20

Ciocoletto, G. (2018). Aristas en el Crisol. Barrio Chino y Mercado Andino: apropiación, comunicación y patrimonio urbano de Buenos Aires. En Primer Congreso VIVIR LA CIUDAD. Patrimonio, diversidad cultural e identidad en la ciudad contemporánea (p. 1-15). Posadas: CICOP.

Ciocoletto, G. (2019). Etnización y Autenticidad del Espacio Público Reflexiones sobre la vocación urbana del Barrio Chino porteño Ethnization and authenticity of Public Space Considerations on the urban vocation of Buenos Aires' Chinatown. En XI Seminario Internacional de Investigación en Urbanismo (p. 1-13). Santiago de Chile: Departament d'Urbanisme i Ordenació del Territori. Universitat Politècnica de Catalunya.

De Certeau, M. (1984). The practice of everyday life. (Steven Rendall [Trad., Ed.]) (1997th ed.). La Jolla, California: University of California Press.

Delgado Ruiz, M. (1999). El animal público. Hacia una antropología de los espacios urbanos. (4a ed.). Barcelona: Editorial Anagrama.

Dinardi, M. C. (2012). Unsettling the culture panacea. The Politics of Cultural Planning, National Heritage and Urban Regeneration in Buenos Aires. [Tesis de doctorado, The London School of Economics and Political Science]. LSE Theses Online. Recuperado el 30 de noviembre de 2018 de http://etheses.lse.ac.uk/id/eprint/589

Ente de Turismo de la Ciudad de Buenos Aires (2013a, 14 feb.). Barrio Chino. Recuperado el 4 de Julio de 2021 de https://turismo.buenosaires.gob.ar/es/otros-establecimientos/barrio-chino

Ente de Turismo de la Ciudad de Buenos Aires (2013b, 12 ago.). Ferias y paseos de compras. Recuperado el 4 de julio de 2021 de https://turismo.buenosaires.gob.ar/es/recorrido/ferias-y-paseos-de-compras

Ente de Turismo de la Ciudad de Buenos Aires (2016, 29 dic.). 9 h. Recuperado el 4 de julio de 2021 de https://turismo.buenosaires.gob.ar/es/atractivo/9-h-compras-en-el-barrio-jud\%C3\%ADo

Ente de Turismo de la Ciudad de Buenos Aires (2020, 13 feb.). Mercados y patios gastronómicos. Recuperado el 4 de julio de 2021 de https://turismo.buenosaires.gob.ar/es/recorrido/mercados-y-patios-gastron\%C3\%B3micos

Folch-Serra, M. (2007). El paisaje como metáfora visual: cultura e identidad en la nación posmoderna. En J. Nogué (Ed.), La construcción social del paisaje (p. 139-162). Madrid: Biblioteca Nueva.

González Viaña, M. del C. (2013). Cambios en la vocación del territorio. Estudio de tres enclaves porteños: Avenida de Mayo, La Boca y Barrio Chino. Universidad Complutense de Madrid. Recuperado el 30 de noviembre de 2018 de http://eprints.ucm.es/24611/1/T35127.pdf

Grimson, A., Ng, G., \& Denardi, L. E. (2016). Las organizaciones de inmigrantes chinos en Argentina. Migración y Desarrollo, 14(enero-junio), 25-73. Recuperado el 30 de noviembre de 2018 de http://www.redalyc.org/html/660/66046498002/

IFLA AMÉRICAS (2018). Descubrir los Paisajes de las Américas diseñar, planificar, conservar y gestionar CARTA DEL PAISAJE DE LAS AMÉRICAS. [Declaratoria]. Conferencia Regional IFLA AR | UAM-A, Ciudad de México, México. Recuperado el 20 de septiembre de 2019 de https://www.ufpe.br/documents/39726/0/08.Carta+de+las+Americas_final_12.pdf/1c7926b74667-4bee-ae7b-fce008af9f9b

INDEC (2010). “Censo Nacional de Población, Hogares y Viviendas 2010: REDATAM + SP” [base de datos]. Buenos Aires: INDEC. Recuperado de http://www.indec.gob.ar

Laborde, M. S. (2011). La alteridad inmigrante en la ciudad del siglo XXI: nuevas formas de construcción del espacio público. CS, 7(enero-junio), 19-44. https://doi.org/10.18046/recs.i7.1037

Lefebvre, H. (1974). The Production of Space. (D. Nicholson-Smith [Trad., Ed.]) (1991st ed.). Oxford-Cambridge: Blackwell Publishing Ltd.

Lefebvre, H. (1996). Writings on Cities (E. Kofman \& E. Lebas, Eds.). London, England: Blackwell.

Mera, G., \& Marcos, M. (2015). Cartografías migratorias urbanas. Distribución espacial de la población extranjera en la Ciudad de Buenos Aires (2010). Geograficando, 11(1). Recuperado el 30 de noviembre de 2018 de http://www.geograficando.fahce.unlp.edu.ar/article/view/Geov11n01a04\%0AResumen 
Nogué, J. (2007). Paisaje, identidad y globalización. Fabrikart: Arte, Tecnología, Industria, Sociedad, (7) 136-145. Recuperado el 5 de julio de 2020 de https://dialnet.unirioja.es/servlet/articulo?codigo=2942259\&orden=1\&info=link

Nogué, J., \& de San Eugenio Vela, J. (2010). Teoría de la comunicación y paisaje. Las geografías del sujeto y la perspectiva interpretativa de la comunicación. Doxa Comunicación: Revista Interdisciplinar de Estudios de Comunicación y Ciencias Sociales, (10), 13-34. Recuperado el 5 de julio de 2020 de https://dialnet.unirioja.es/servlet/articulo?codigo=3191530\&orden=0\&info=link

Nogué, J., \& de San Eugenio Vela, J. (2017). La contribución del paisaje visual en la generación de marcas territoriales. Boletín de La Asociación de Geógrafos Españoles, 74,143-160. https://doi.org/10.21138/bage.2448

Nogué, J., de San Eugenio Vela, J., \& Sala, P. (2019). La implementación de indicadores de lo intangible para catalogar el paisaje percibido. El caso del Observatorio del Paisaje de Cataluña. Revista de Geografía Norte Grande, (72), 75-91. http://dx.doi.org/10.4067/S0718-34022019000100075

Peñalosa, R., Alcántara, S., Jankilevich, C., Veras, L., \& Ocejo Cázares, M. T. (2018). Carta del paisaje de las Américas. Astrágalo: Cultura de La Arquitectura y La Ciudad, (25), 125-133. Recuperado el 11 de julio de 2020 de https://dialnet.unirioja.es/servlet/articulo?codigo $=7563357$

Proyecto de Ley 402-D-2005 (2005), Legislatura Porteña, 14 de septiembre de 2006.

Said, E. W. (2002). Orientalismo. Barcelona: Random House Mondadori.

Sassone, S. M., \& Mera, C. (2007). Barrios de migrantes, espacios interculturales: coreanos y bolivianos en la Ciudad de Buenos Aires. En XXVI Congreso de la Asociación Latinoamericana de Sociología. Asociación Latinoamericana de Sociología (p. 0-19). Guadalajara: ALAS. Recuperado el 6 de enero de 2016 de http://www.aacademica.org/000-066/1015

Thrift, N. (2004). Intensities of feeling: towards a spatial politics of affect. Geografiska Annaler, 86 B(1), 57-78. https://doi.org/10.1111/j.0435-3684.2004.00154.x/

Torres, R. A. (2016). Los Barrios Chinos en Buenos Aires: entre diversidades, tensiones e interculturalidad. Diversidad, 11(Dic 2015-Jun 2016), 1-24. Recuperado el 30 de noviembre de 2018 de http://www.diversidadcultural.net/articulos/nro011/11-02-Mag-Rayen-Amancay-Torres.pdf

Zubelzu Mínguez, S., \& Allende Álvarez, F. (2015). El concepto de paisaje y sus elementos constituyentes: requisitos para la adecuada gestión del recurso y adaptación de los instrumentos legales en España. Cuadernos de Geografía: Revista Colombiana de Geografía, 24(1). Recuperado el 20 de julio de 2020 de https://revistas.unal.edu.co/index.php/rcg/article/view/41369/50469.

Editor: Fábio Duarte

Recibido: 18 ago. 2020

Aprobado: 19 mayo 2021 